\title{
Influence of Air Temperature on the Performance of Different Water-Reducing Admixtures with Respect to the Properties of Fresh and Hardened Mortar
}

\author{
Wilson Ricardo Leal Silva, ${ }^{1}$ Luiz Roberto Prudêncio Jr., ${ }^{1}$ Alexandre Lima Oliveira, ${ }^{2}$ \\ Gabriela Damo, ${ }^{1}$ and Eduardo Tochetto ${ }^{1}$ \\ ${ }^{1}$ Universidade Federal de Santa Catarina, Campus Universitário, Eng.Civil, Bl. B/s.114, 88040970 Florianópolis, Brazil \\ ${ }^{2}$ Instituto Federal de Santa Catarina, Avenida Mauro Ramos 950, 88020-300 Florianópolis, Brazil \\ Correspondence should be addressed to Wilson Ricardo Leal Silva, wilsonecv@gmail.com
}

Received 24 May 2010; Revised 4 September 2010; Accepted 11 October 2010

Academic Editor: K. Soudki

Copyright (C) 2010 Wilson Ricardo Leal Silva et al. This is an open access article distributed under the Creative Commons Attribution License, which permits unrestricted use, distribution, and reproduction in any medium, provided the original work is properly cited.

\begin{abstract}
The performance of water-reducing admixtures used in concrete is affected by the weather conditions to which the concrete mixture is exposed. The most used WRAs are lignosulfonate, naphthalene, and polycarboxylate. However, they react differently to weather conditions, especially to air temperature. Therefore, it can be useful to evaluate how temperature affects admixture performance. In this study, the performance of three admixtures (naphthalene, lignosulfonate, and polycarboxylate) was evaluated at 15,25 , and $35^{\circ} \mathrm{C}$ by means of the flow table test, mixture air content, and compressive strength. Moreover, mixture temperature was monitored and time-temperature curves were plotted in order to assess whether the admixtures affected cement hydration reactions at different temperatures. The final results indicate that an increase in temperature leads to an increase in saturation dosage; lignosulfonate had the most pronounced retarding effect, followed by polycarboxylate, and finally, naphthalene, and considering the weather conditions in the area where the study was carried, the final finding would be that the naphthalene-based admixture had the best performance.
\end{abstract}

\section{Introduction}

Over the past several decades, admixtures have increasingly been used to modify specific properties of concrete mixtures and to reduce costs. Such modifications often lead to an increase in workability, a reduction in water content, better control over setting time, and an increase in strength. Admixture effectiveness, with respect to both fresh and hardened concrete, depends on variables related to the cement, aggregates, and admixtures themselves, and also depends on external factors such as air temperature. Water-reducing admixtures stand out among the most used in concrete. They can be composed of various active ingredients, including lignosulfonate, naphthalene, and polycarboxylate. Such admixtures cause cement grains to disperse-and thus to have a plasticizing effect-through mechanisms of electrostatic repulsion and steric hindrance $[1,2]$. Electrostatic repulsion, which explains how naphthalene and lignosulfonates work, is brought about by the adsorption of an (electrostatically negative) sulfonic group onto the surface of the cement grain, giving it a negative electrostatic charge. The predominance of negative charges on the surface of the grains leads to repulsion between particles, thus releasing the water that is held between them. In the case of steric hindrance, the mechanism that describes how polycarboxylates work is that the particles adsorbed onto the cement grain have long side chains, which have greater repulsive capacity because they serve as physical impediments that prevent grains from bonding.

Water reduction allows a decrease in the amount of cement used, which in turn reduces costs. However, waterreducing admixtures are based on various active ingredients. These may behave differently at given temperatures. Such variations become a concern for concrete plants and 
TABle 1: Physical properties of the sand.

\begin{tabular}{lcc}
\hline Properties & $\mathrm{A}$ & $\mathrm{B}$ \\
\hline Fineness modulus & 0.93 & 3.04 \\
Maximum grain size $(\mathrm{mm})$ & 0.60 & $>2.4$ \\
Minimum grain size $(\mathrm{mm})$ & 0.075 & $<0.075$ \\
Dusty material content $(\%)$ & 0.60 & 6.8 \\
Density $\left(\mathrm{kg} / \mathrm{dm}^{3}\right)$ & 2.650 & 2.664 \\
Absorption $(\%)$ & 0.18 & 0.31 \\
\hline
\end{tabular}

manufactures of precast concrete because the behavior of the concrete varies according to the season during which it was produced. In this context, the goal of this study is to assess the effect of temperature and admixture dosage on the performance-in fresh and hardened concrete-of the three water-reducing admixtures mentioned above.

\section{Materials}

The tests conducted in this study were carried out with mortar, as the performance of admixtures in concrete was found to correlate well with their performance in mortar $[3,4]$. Pozzolanic cement (CP IV 32) with $28 \%$ fly ash content [5] was used together with two types of sand, that is, natural sand from dunes and from crushed rocks. Sand composition (in volume) was 35\% natural fine sand and 65\% manufactured sand. This composition has been found to be an excellent proportion by a concrete plant located in the area where this study was conducted. The physical properties of the sand (presented in Table 1) were assessed based on instructions found in [6-8].

Three water-reducing admixtures produced by the same manufacturer were tested. Each admixture had a different active ingredient: lignosulfonate $(L): 44 \%$ solid content and 0.13\%, 0.26\%, 0.40\% dosages; naphthalene $(N): 40 \%$ solid content and $0.24 \%, 0.32 \%, 0.40 \%$ dosages; polycarboxylate $(P): 30 \%$ solid content and $0.03 \%, 0.06 \%, 0.09 \%$ dosages. The above-mentioned dosages were measured with reference to cement mass and solid content (w.c \%). These dosages were chosen based on values used to produce conventional concrete in concrete plants and recommended by the admixture manufacturers - the exception being polycarboxylate, which was employed at lower dosages, given its superior water-reducing capability.

\section{Methodology}

All of the experimental materials were kept in EPS (expanded polystyrene foam) boxes under controlled temperatures of $15^{\circ} \mathrm{C}, 25^{\circ} \mathrm{C}$, and $35^{\circ} \mathrm{C}$ for 24 hours. The nomenclature employed to designate each mortar mixture refers to three characteristics: the active ingredient, followed by the dosage, and, finally, the temperature at which it was studied; for example, L0.13-15 refers to a mixture containing $0.13 \%$ lignosulfonate and tested at $15^{\circ} \mathrm{C}$.

To produce all of the mortars, a $0.55 \mathrm{w} / \mathrm{c}$ ratio was maintained and the above-mentioned admixture dosages were used. This w/c ratio is used by one of the concrete plants in the area where the study was conducted to produce concrete with specified compressive strength of $35,0 \mathrm{MPa}$ at 28 days. Sand content would vary so that the initial consistency of the mortars, measured by means of the flow table test (before any strokes), would fall within a range of 180 to $200 \mathrm{~mm}$. That is, for each mortar a mixture was first prepared with proportions equal to $1: 1: 0.55$ (cement: mixed sand: water); the specified admixture was then introduced into the mixture, and finally, more sand was mixed in until the desired (initial) consistency was achieved. Total mixing time was 5 minutes. The mixing procedure applied to produce the mortar mixtures was kept the same, and this is presented as follows: (1) $0 \mathrm{~s}-30 \mathrm{~s}$, mixing of dry materials mixed together; (2) $30 \mathrm{~s}-1 \mathrm{~min} 30 \mathrm{~s}$, addition of water; (3) $1 \mathrm{~min} 30 \mathrm{~s}-2 \mathrm{~min} 30 \mathrm{~s}$, scrapping of materials from the walls of bowl; (4) 2 min $30 \mathrm{~s}-3 \mathrm{~min}$, addition of admixture; (5) 3 min- 4 min, mixing of the base mortar; (6) 4 min- $5 \mathrm{~min}$, addition of aggregates, according to the temperature of the mortar, in order to obtain the desired consistency for the mortar $(210 \pm 10 \mathrm{~mm})$.

As mentioned above, once mixed, the initial consistency of the mortars was determined using the flow test (the truncated cone was raised allowing the concrete to flow out, without applying strokes) and its air content was measured.

Next, one part of the mortar was stored into EPS boxes (Figure 1(a)) in order to determine the initial setting times indirectly through the analysis of time-temperature curves. The temperature (in addition to air temperature) was monitored using type $\mathrm{K}$ thermocouples connected to a data logger and computer (Figure 1(b)). Several studies have shown that the initial setting is characterized by a highly exothermic reaction, which occurs due to the hydration of cement compounds. Given this fact, the mortar was monitored to establish the exact time when its temperature starts to increase, which was taken to be the initial setting time. However, it is important to consider that the initial setting time determined by time-temperature curves is connected to the hydration kinetics. Therefore, the results presented herein represents an approximation of the initial setting time obtained by resistance penetration test.

The second part of the mortar mixtures was stored in containers, which were then sealed and kept in a climatecontrolled room where mortar consistency was assessed once every 20 minutes, for an hour.

Following this, two $5 \times 10 \mathrm{~cm}$ (diameter $\times$ height) cylindrical specimens were molded in order to evaluate mortar compressive strength after 14 days. In order to exclude the influence of different curing conditions for each one of the different temperatures, the specimens were kept for one day in mould in climate-controlled room, unmolded, and then kept for another 13 days in 100\% RH room until they were tested.

\section{Results and Analysis of Results}

Table 2 presents the test results. 
TABle 2: Test results.

\begin{tabular}{|c|c|c|c|c|c|c|c|c|c|c|c|c|c|}
\hline \multirow{3}{*}{$\begin{array}{l}\text { Admixture } \\
\text { active } \\
\text { ingredient }\end{array}$} & \multirow{3}{*}{$\begin{array}{l}\text { Admixture } \\
\text { dosage } \\
\text { (\% w.c.) }\end{array}$} & \multicolumn{12}{|c|}{ Temperature } \\
\hline & & $15^{\circ} \mathrm{C}$ & $25^{\circ} \mathrm{C}$ & $35^{\circ} \mathrm{C}$ & $15^{\circ} \mathrm{C}$ & $25^{\circ} \mathrm{C}$ & $35^{\circ} \mathrm{C}$ & $15^{\circ} \mathrm{C}$ & $25^{\circ} \mathrm{C}$ & $35^{\circ} \mathrm{C}$ & $15^{\circ} \mathrm{C}$ & $25^{\circ} \mathrm{C}$ & $35^{\circ} \mathrm{C}$ \\
\hline & & \multicolumn{3}{|c|}{ Sand mix/cement $(\mathrm{kg} / \mathrm{kg})$} & \multicolumn{3}{|c|}{ Air content $(\%)$} & \multicolumn{3}{|c|}{ Initial setting time $(\mathrm{h})$} & \multicolumn{3}{|c|}{ Compressive strength $*(\mathrm{MPa})$} \\
\hline \multirow{3}{*}{$\mathrm{L}$} & 0.13 & 2.22 & 2.18 & 1.99 & 1.6 & 1.6 & 2.5 & 8.9 & 4.6 & 4.7 & 29.7 & 30.9 & 29.9 \\
\hline & 0.26 & 2.56 & 2.53 & 2.38 & 2.2 & 2.5 & 1.3 & 18.4 & 8.6 & 8.5 & 32.5 & 30.6 & 32.2 \\
\hline & 0.40 & 2.75 & 2.80 & 2.77 & 4.4 & 2.7 & 3.1 & 32.8 & 15.2 & 16.5 & 31.3 & 30.9 & 29.5 \\
\hline \multirow{3}{*}{$\mathrm{N}$} & 0.24 & 2.26 & 2.34 & 2.25 & 0.9 & 1.2 & 0.7 & 5.3 & 2.8 & 2.9 & 28.5 & 28.2 & $* *$ \\
\hline & 0.32 & 2.50 & 2.53 & 2.58 & 1.9 & 1.1 & 0.9 & 5.6 & 3.0 & 2.9 & 28.8 & 28.3 & $* *$ \\
\hline & 0.40 & 2.78 & 2.86 & 2.87 & 1.6 & 2.0 & 1.6 & 5.6 & 2.9 & 3.0 & 25.6 & 27.0 & 28.2 \\
\hline \multirow{3}{*}{$\mathrm{P}$} & 0.03 & 2.10 & 2.34 & 1.95 & 1.0 & 1.2 & 0.8 & 4.8 & 2.8 & 2.1 & 28.6 & 28.3 & 29.0 \\
\hline & 0.06 & 2.88 & 2.71 & 2.77 & 4.5 & 3.9 & 3.8 & 7.8 & 4.4 & 4.8 & 27.3 & 27.9 & 27.2 \\
\hline & 0.09 & 3.20 & 3.26 & 3.14 & 5.7 & 4.7 & 2.7 & 9.8 & 3.5 & 2.9 & 27.6 & 27.5 & 26.5 \\
\hline
\end{tabular}

* For each case, the compressive strength of both specimens was assessed and the higher of the two values obtained was considered to be the actual compressive strength value, which is indicated here in each cell.

** The test was not carried out due to the problems that occurred when unmolding the specimens.

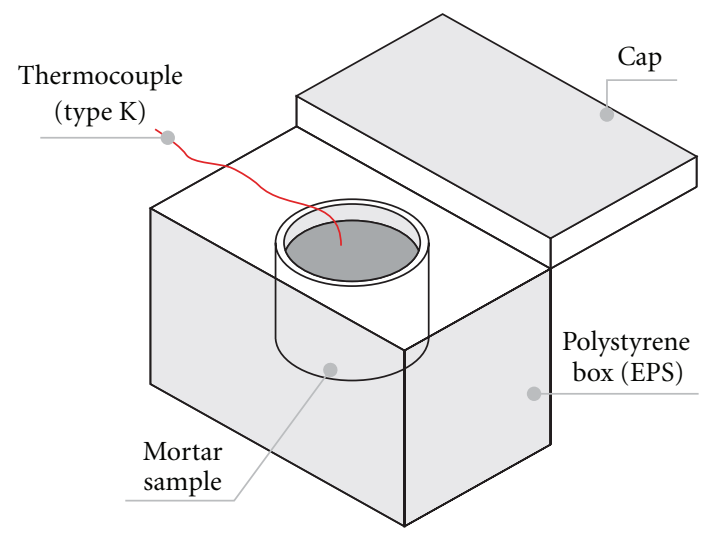

(a)

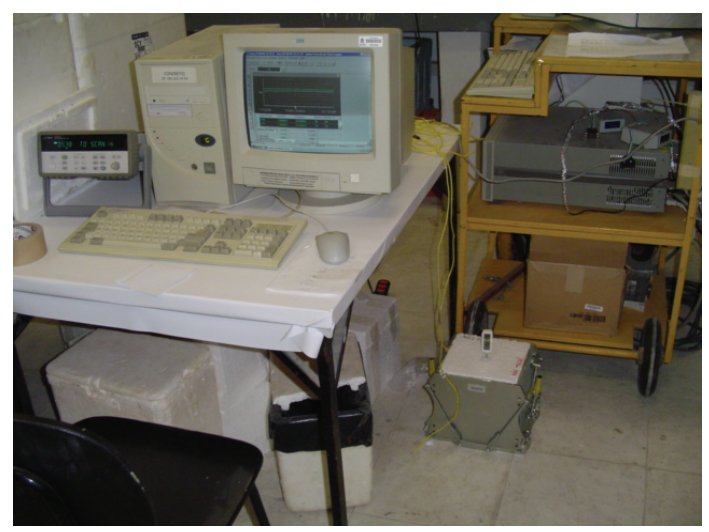

(b)

FIgURE 1: (a) EPS box and (b) datalogger used to measure and determine the time-temperature curve for the mortar mixtures.

4.1. Effect of Temperature Variation and Admixture Dosage on Initial Consistency and Flow Loss. With respect to initial consistency, the results presented in Table 2 and Figure 2 indicate that regardless of temperature, the polycarboxylatebased admixture is the most effective as it allows mixing larger amounts of sand, even at a low dosage (see Table 2). Naphthalene and lignosulfonate behaved similarly only at temperatures above $25^{\circ} \mathrm{C}$. At $T=15^{\circ} \mathrm{C}$, the performance of lignosulfonate was slightly better than that of naphthalene.

In regard to capacity for maintaining consistency (Figures 3(a)-3(c)), polycarboxylate behaves as expected for the specified dosages: at a fixed temperature, total flow loss increases as admixture dosage is raised. The higher the admixture dosage, the higher the sand content and the lower the cement paste/mortar ratio; flow loss therefore occurs more rapidly due to stiffening of the cement paste.

With respect to the influence of temperature variation on flow loss, as observed in Figures 4(a)-4(c), the low polycarboxylate dosages used here were not conducive to obtaining conclusive results for this admixture. The flow loss curves in Figures 4(a)-4(c) all coincide, except for the P-0.0625 curve.

In the case of naphthalene, when considering the effect of admixture dosage (see Figures 5(a)-5(c)), it can be surmised that $0.40 \%$ exceeded the saturation dosage at $T=15^{\circ} \mathrm{C}$, given that flow loss was less important for $\mathrm{N}-0.40-15$ than for $\mathrm{N}-0.32-15$. With a $0.40 \%$ dosage, the naphthalene that was mixed into the mortar was not consumed entirely, thus yielding less flow loss, because of a residual amount of admixture.

An increase in temperature from $15^{\circ} \mathrm{C}$ to $25^{\circ} \mathrm{C}$ affects reactions kinetically, accelerating them, therefore raising the saturation point; in other words, at $T=25^{\circ} \mathrm{C}, 0.40 \%$ is below the saturation dosage for naphthalene. Consequently, any residual amount of admixture was reduced, and flow loss was greater for $\mathrm{N}-0.40-25$ than for $\mathrm{N}-0.32-25$. At $T=35^{\circ} \mathrm{C}$, flow loss was similar across the mixtures because, in this case, it is attributed to accelerated admixture consumption due to the rise in temperature. It can therefore be concluded (for the dosages used in this study) that, contrary to what was observed at $15^{\circ} \mathrm{C}$, increasing naphthalene dosage at $35^{\circ} \mathrm{C}$ did not contribute to maintaining consistency. 


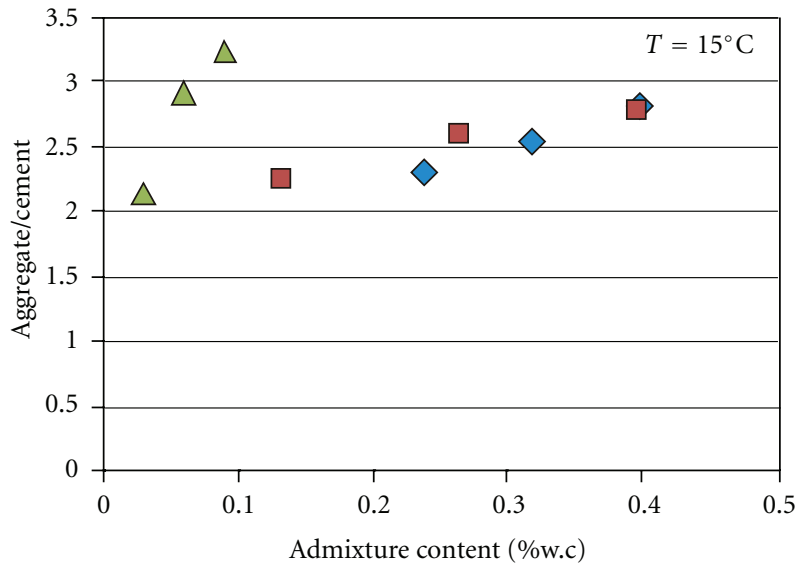

(a)

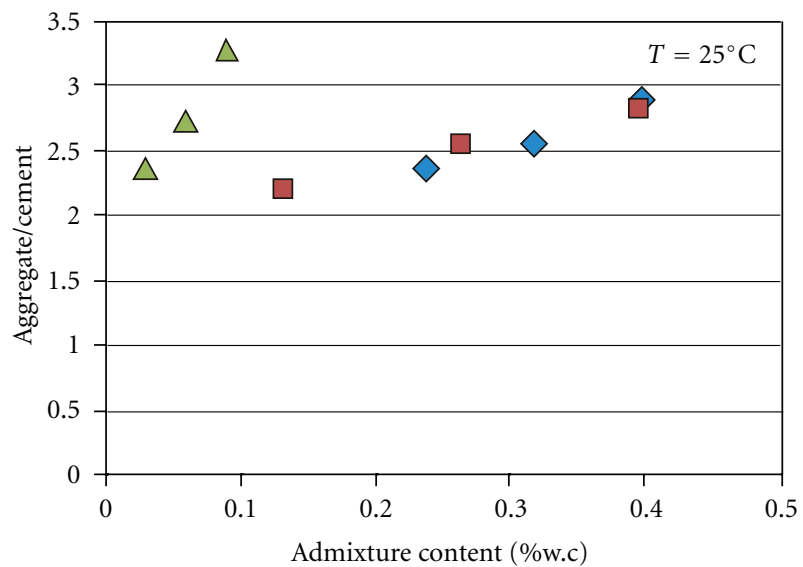

(b)

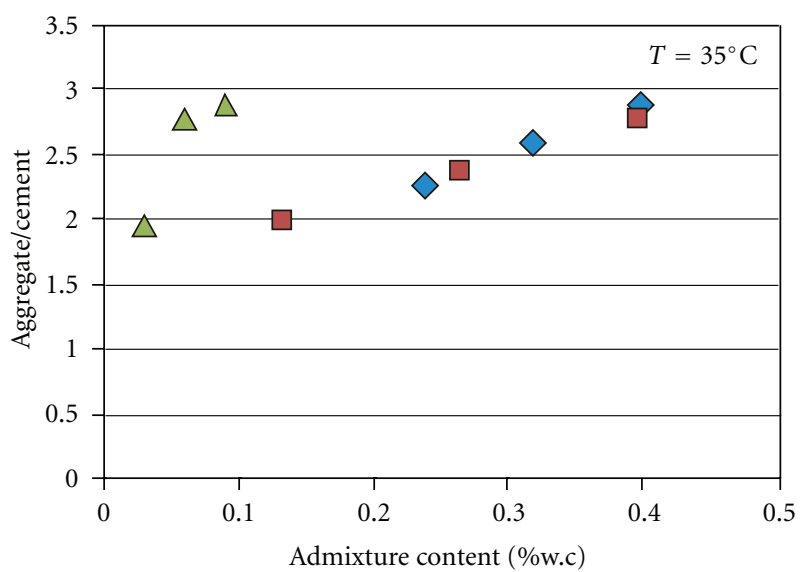

Lignosulfonate

$\diamond$ Naphthalene

$\triangle$ Polycarboxylate

(c)

FIGURE 2: Effect of temperature variation and admixture dosage on initial consistency.

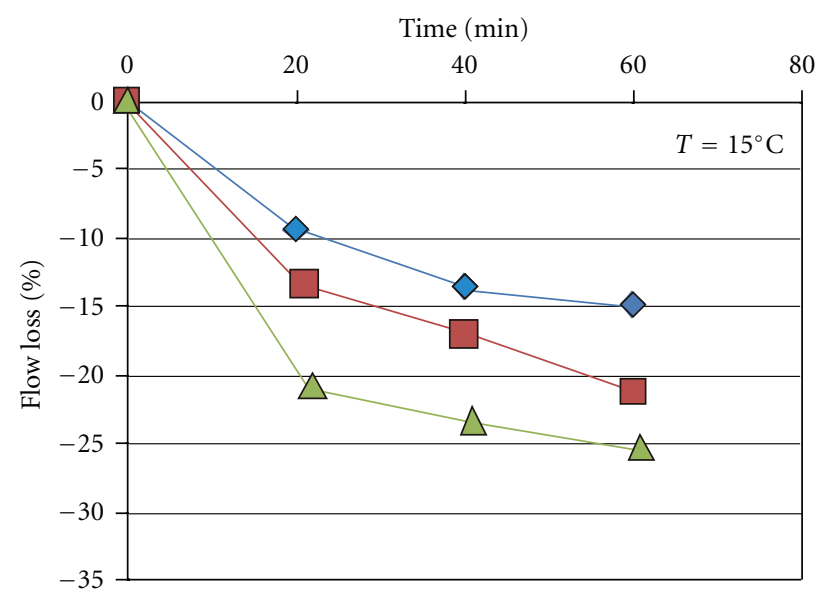

(a)

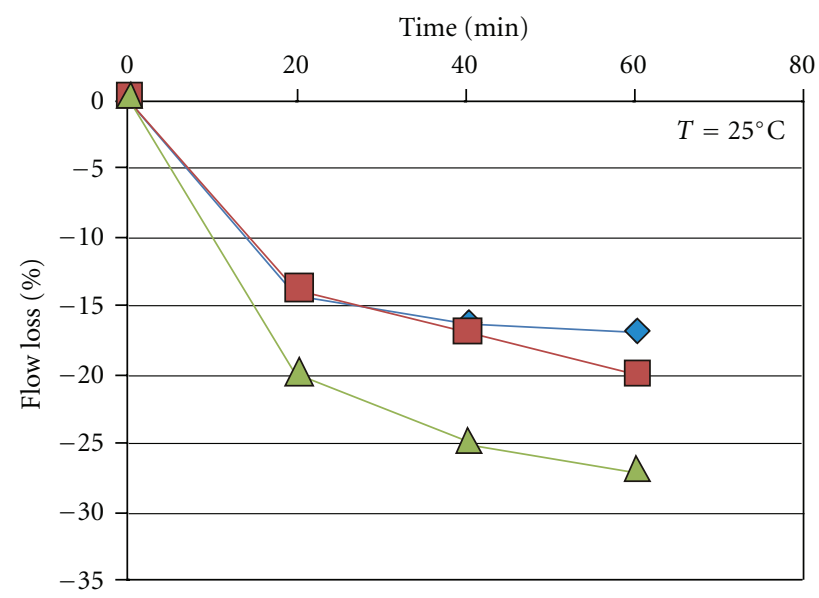

(b)

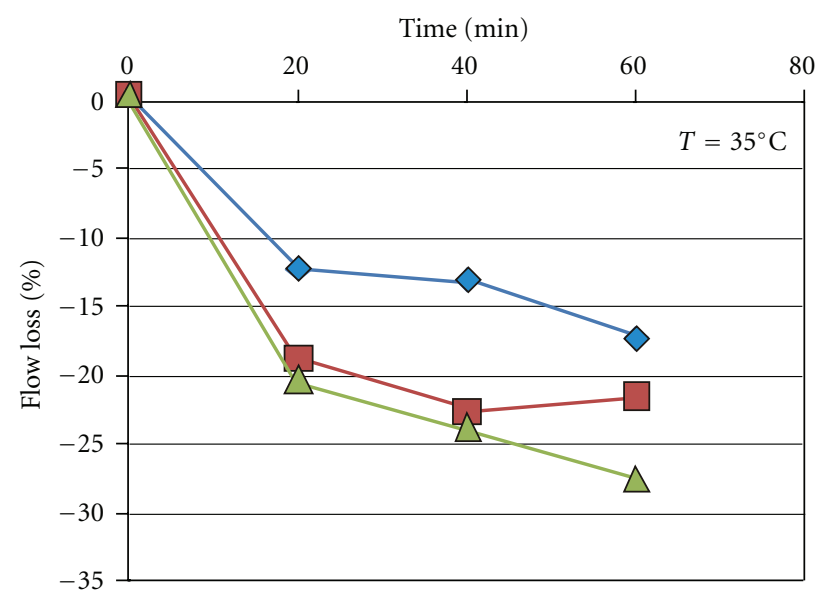

(c)

FIGURE 3: Effect of admixture dosage on flow loss-polycarboxylate. 


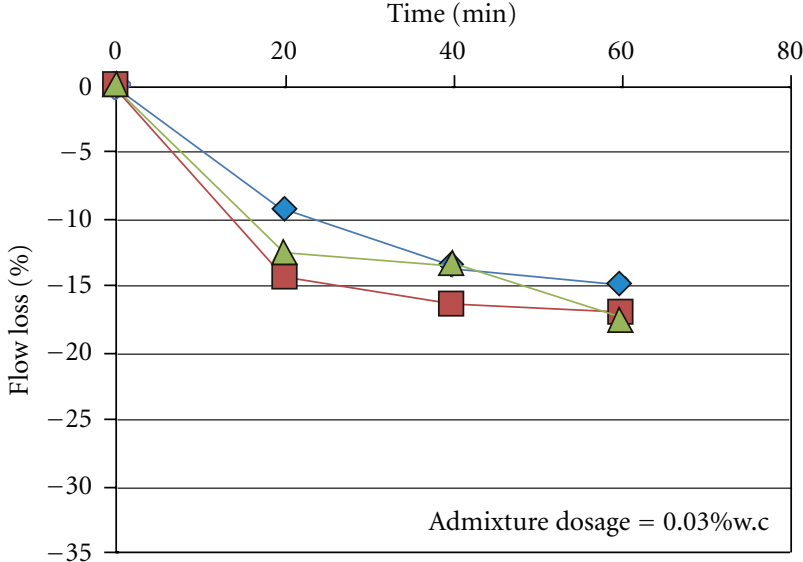

(a)

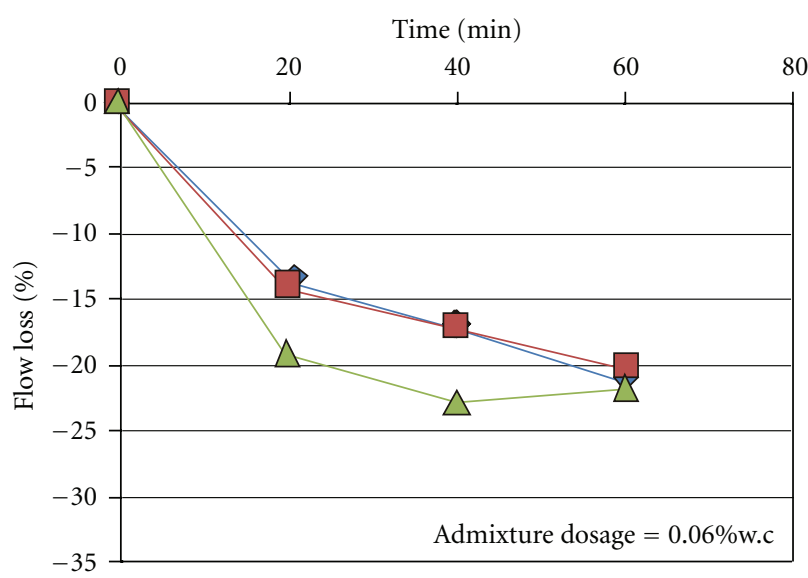

(b)

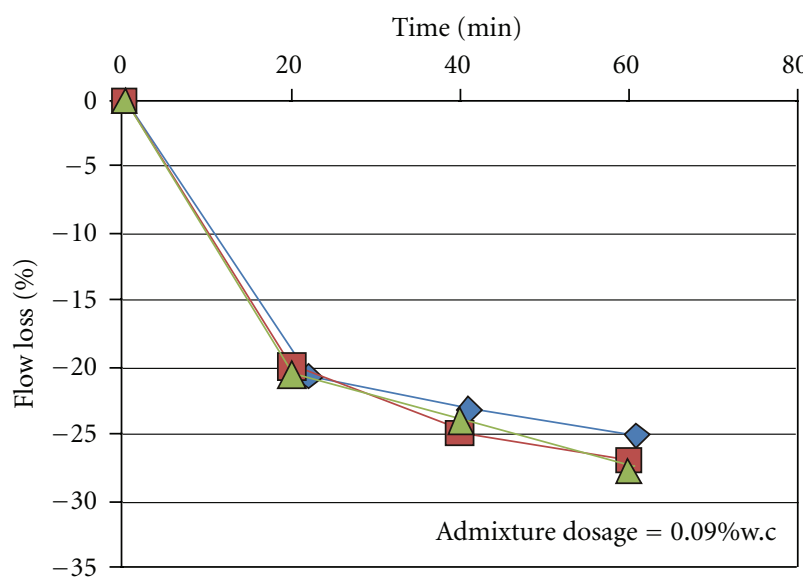

(c)

Figure 4: Effect of temperature variation on flow loss-poly-carboxylate.

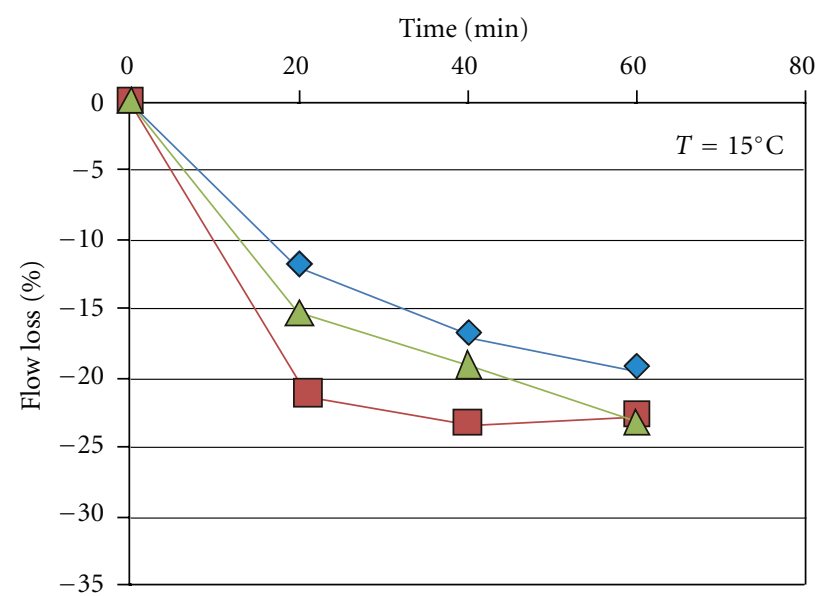

(a)

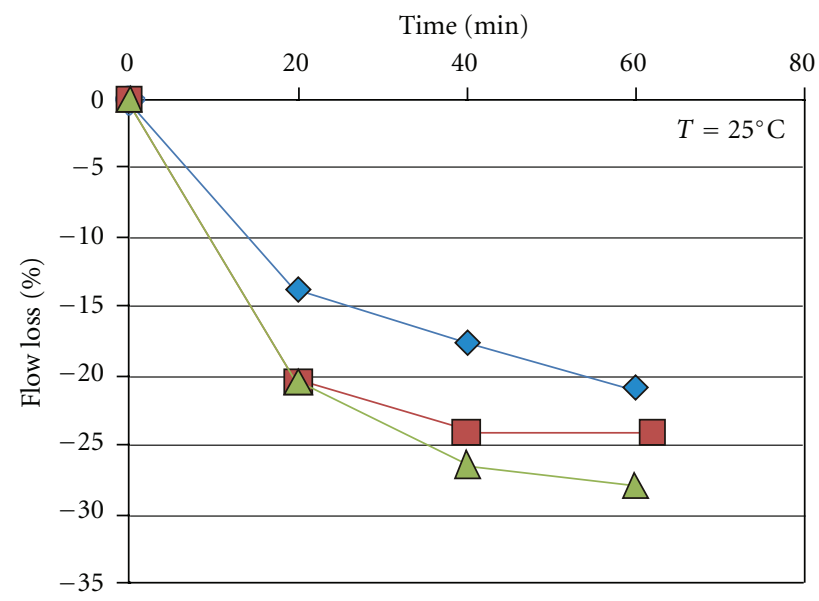

(b)

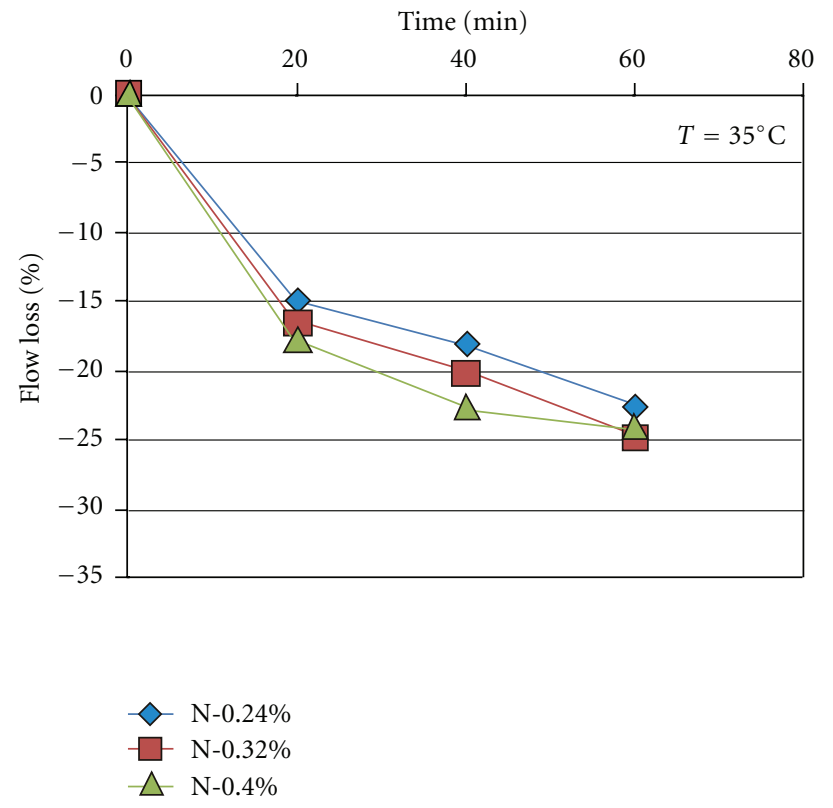

(c)

FIgURE 5: Effect of admixture dosage on flow loss-naphthalene. 
In the case of lignosulfonate, when considering the effect of admixture dosage (Figures 6(a)-6(c)), it is likely that $0.40 \%$ exceeded, by far, the saturation point at $T=15^{\circ} \mathrm{C}$ and that this dosage was the cause of an appreciable segregation observed for this particular mixture. Thus, despite the presence of a residual amount of admixture, consistency was even more tightly linked to friction between particles in this situation, and, accordingly, flow loss was greater than could be expected. Still considering flow loss at $T=$ $15^{\circ} \mathrm{C}$, it is likely that the $0.26 \%$ dosage was also above the saturation point, yet, no segregation was observed at this dosage. Consequently, flow loss was less significant, given that the effect of the admixture was prolonged.

Regarding the influence of temperature on flow loss for the mortars with naphthalene-based and lignosulfonatebased admixtures, Figures $7(\mathrm{a})-7(\mathrm{c})$ and Figures $8(\mathrm{a})-8(\mathrm{c})$ show that as the temperature rises from $T=15^{\circ} \mathrm{C}$ to $T=25^{\circ} \mathrm{C}$, flow loss increases, whereas it decreases when the temperature rises from $T=25^{\circ} \mathrm{C}$ to $T=35^{\circ} \mathrm{C}$. Note that the effect of temperature could not be determined for mixtures $\mathrm{N}-0.24-15 ; 25 ; 35$ and L-0.13-15; 25; 35 given the low admixture dosages used in these cases (see Table 2).

4.2. Effect of Temperature Variation and Admixture Dosage on Air Content. With respect to air content (see Figures 9(a)$9(\mathrm{c})$ ), results show that polycarboxylate has the greatest airentraining capability, especially at dosages above 0.06 ; it is followed by lignosulfonate and naphthalene, respectively.

In regard to the effect of temperature variation on air content (see Table 2), results indicate that the naphthalenebased admixture is the least influenced by temperature. For lignosulfonate and polycarboxylate, air content tends to decrease as temperature rises, except at low dosages.

4.3. Effect of Temperature Variation and Admixture Dosage on Initial Setting Time. The time-temperature curves obtained for each one of the mortars produced are presented in Figures 10 (a)-10(c). The initial setting time defined for the mixtures is surmised in Table 2.

In regard to the effect of temperature variation on the initial setting time (Figures 11(a)-11(c)), the results obtained indicate that an increase in temperature from $25^{\circ} \mathrm{C}$ to $35^{\circ} \mathrm{C}$ had little effect on initial setting time, regardless of the active ingredient. However, dropping the temperature to $T=15^{\circ} \mathrm{C}$ delayed initial setting in all cases. It is surmised that, below $25^{\circ} \mathrm{C}$, hydration reactions are slowed down considerably.

With respect to the influence of admixture dosage, naphthalene content had the least effect on initial setting time, followed by polycarboxylate dosage and lignosulfonate dosage, respectively. The potent retarding effects of lignosulfonate-based admixtures are well known and amply discussed in the literature $[1,9,10]$.

The variation in the initial setting time could also be attributed to the different aggregate/cement content in the mortar mixtures. However, the results presented in Figures 11(a)-11(c) indicate that, for the mixes herein analyzed and particularly for the lignosulfonate, the influence of the admixture dosage is more pronounced than the variation in the aggregate/cement content.

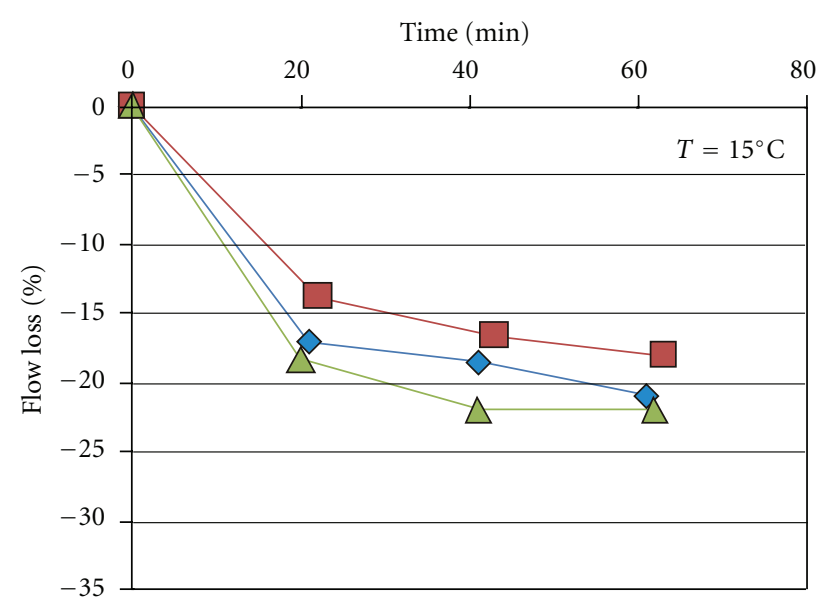

(a)

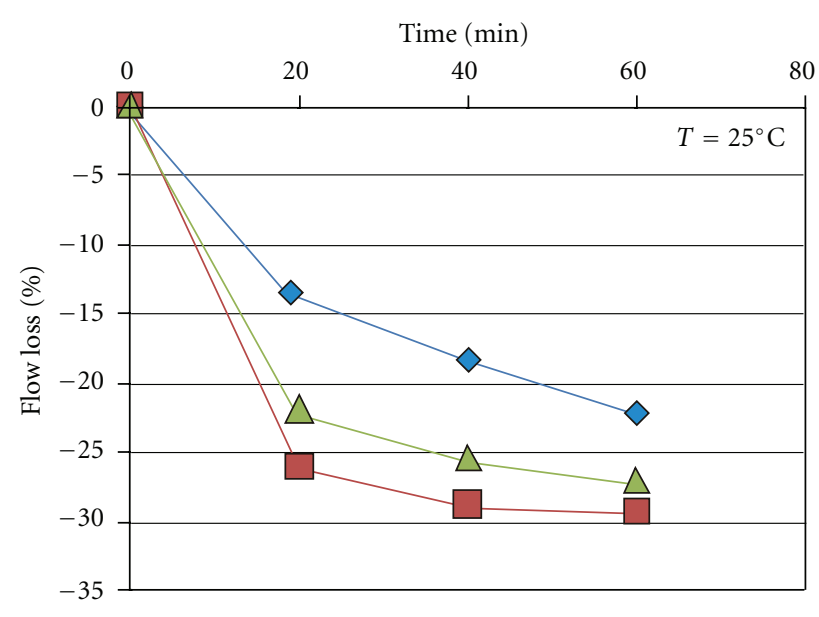

(b)

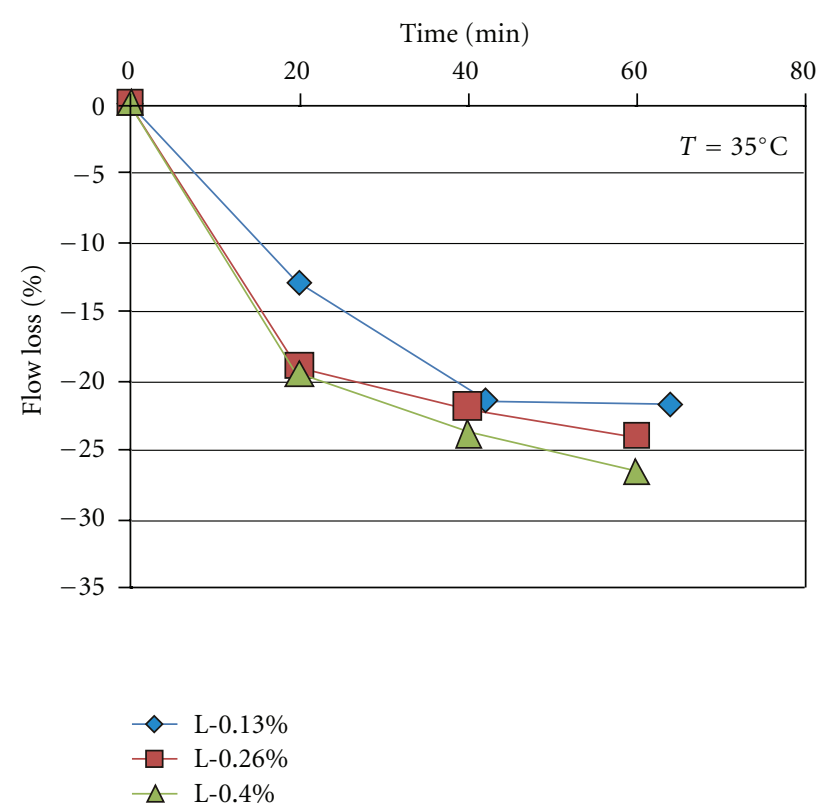

(c)

FIGURE 6: Effect of admixture dosage on flow loss—lignosulfonate. 


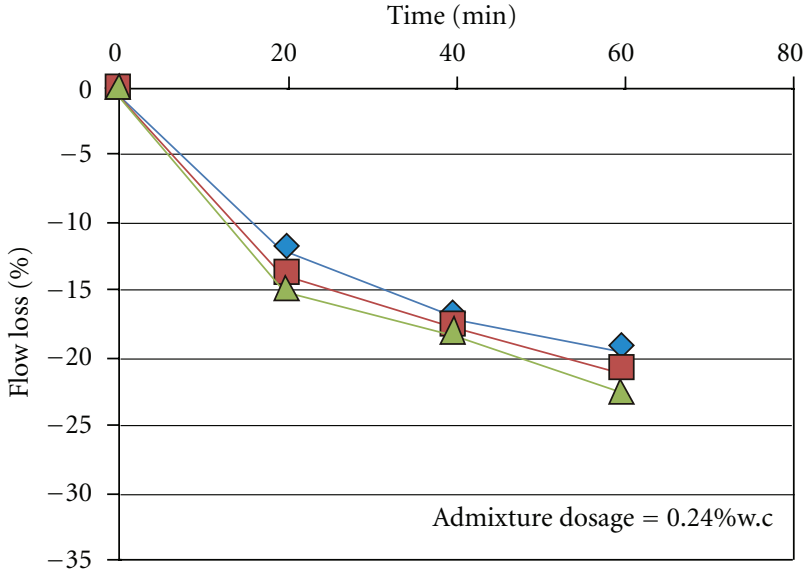

(a)

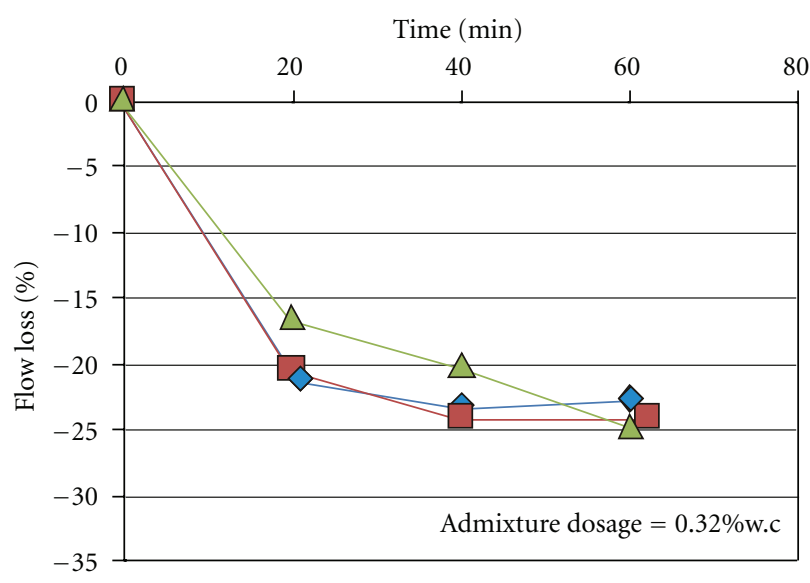

(b)

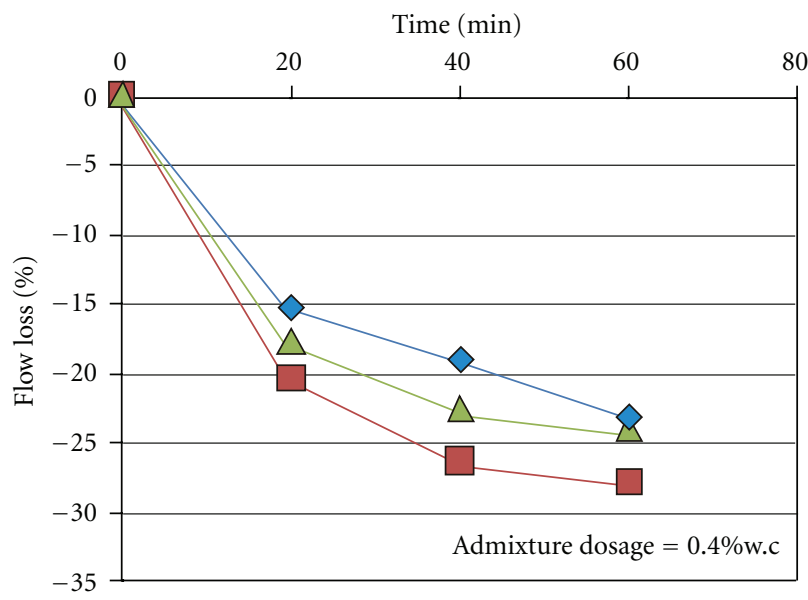

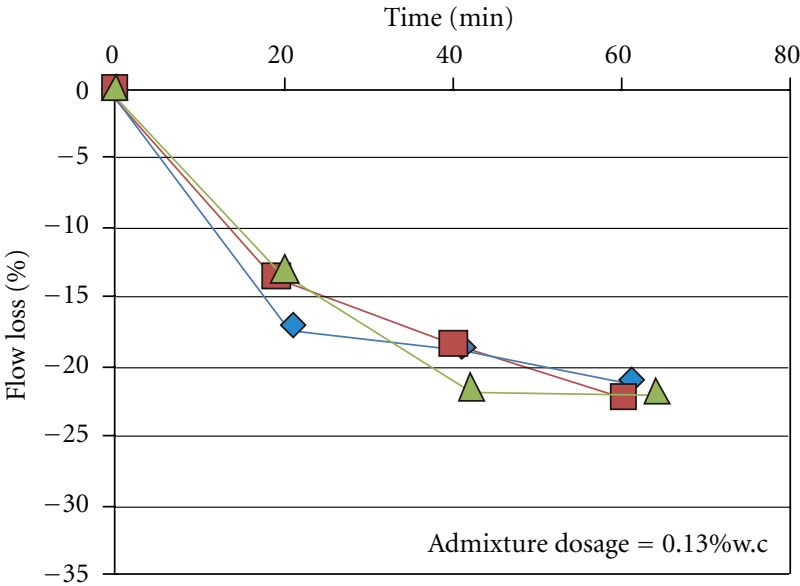

(a)

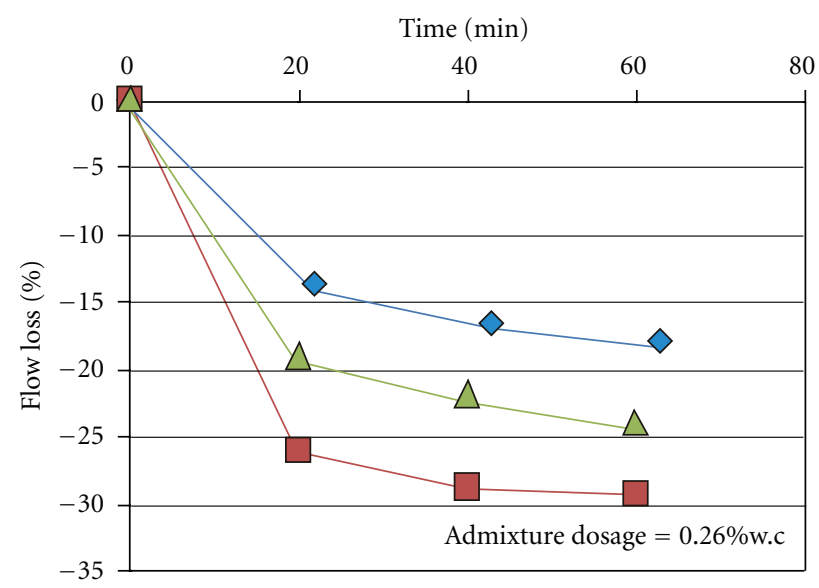

(b)

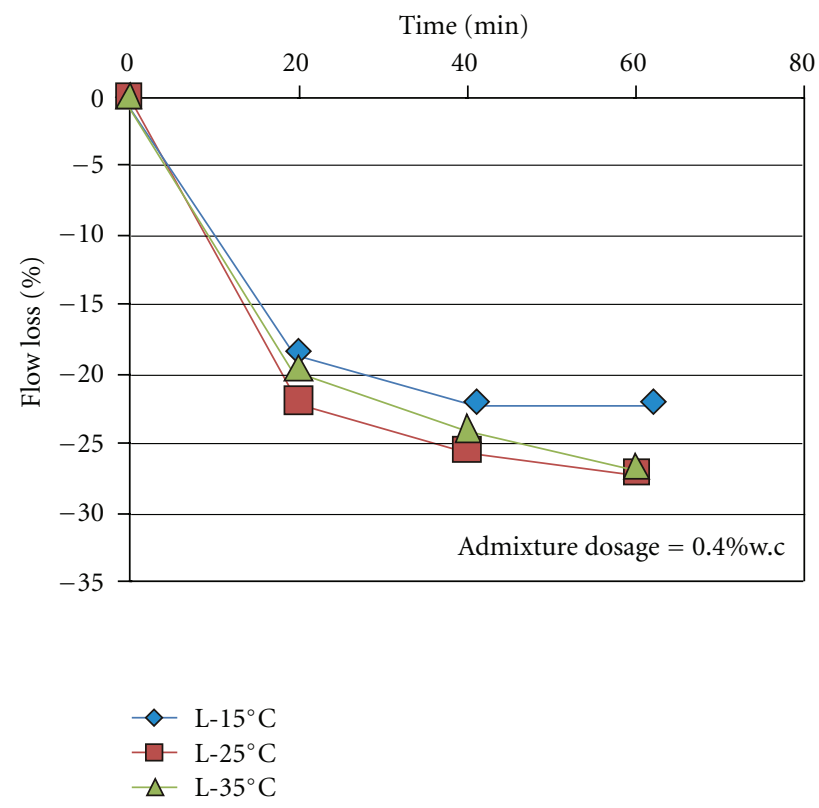

(c)

Figure 8: Effect of temperature variation on flow loss-lignosulfonate
FIGURE 7: Effect of temperature variation on flow loss-naphthalene 


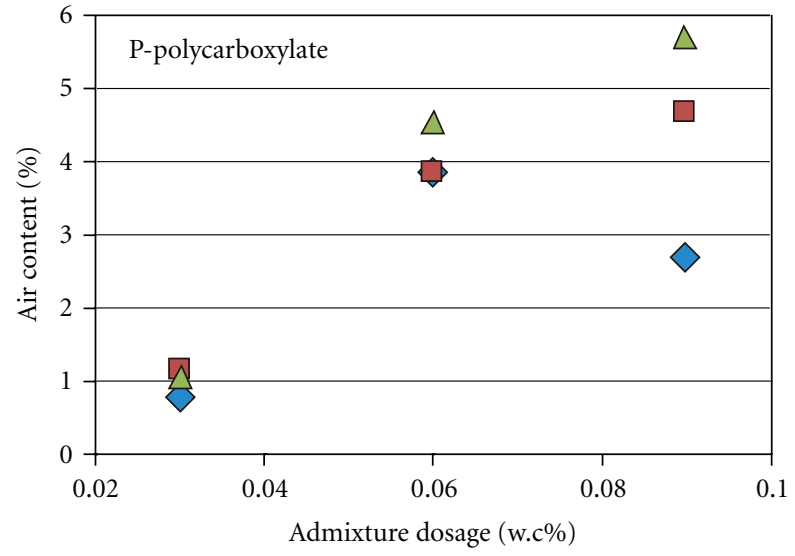

(a)

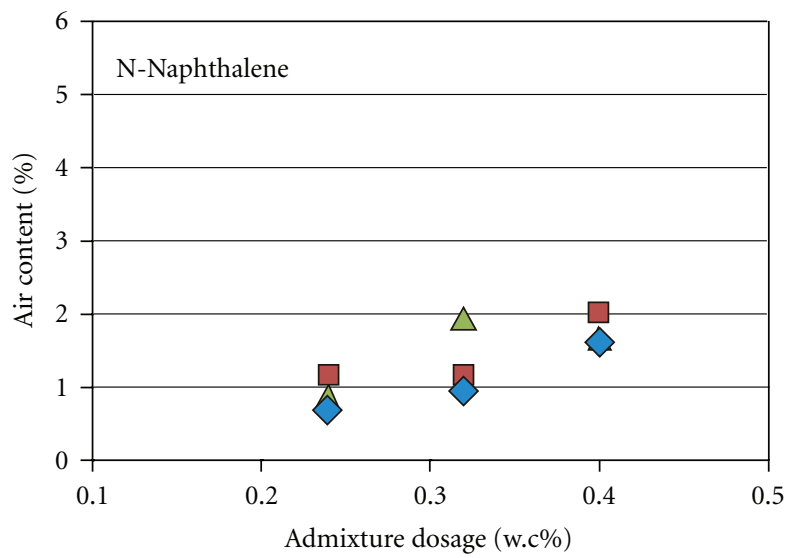

(b)

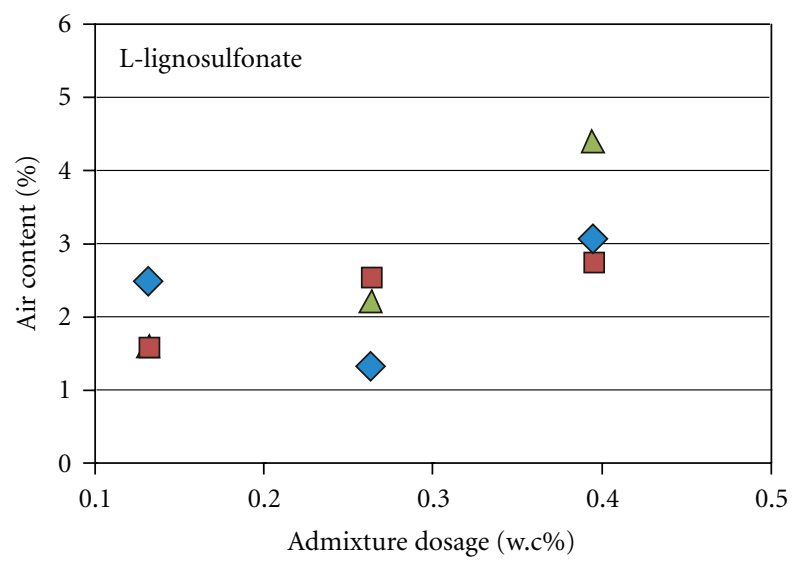

$\triangle T=15^{\circ} \mathrm{C}$

$T=25^{\circ} \mathrm{C}$

$\mathrm{T}=35^{\circ} \mathrm{C}$

(c)

FIGURE 9: Effect of temperature variation and admixture dosage on air content.

4.4. Effect of Temperature Variation and Admixture Dosage on Compressive Strength. Considering the effect of the admixture dosage on compressive strength (Figures 12(a)-12(c)),

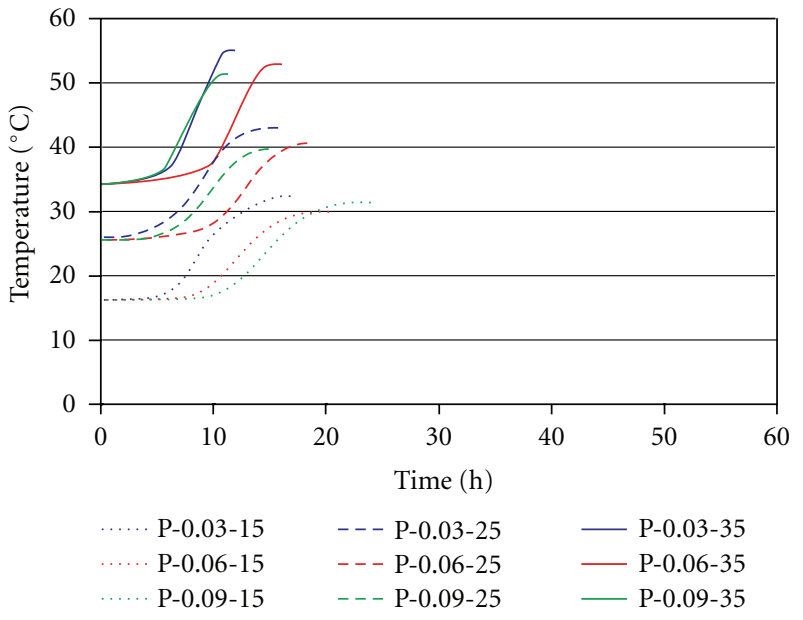

(a) Policarboxilate
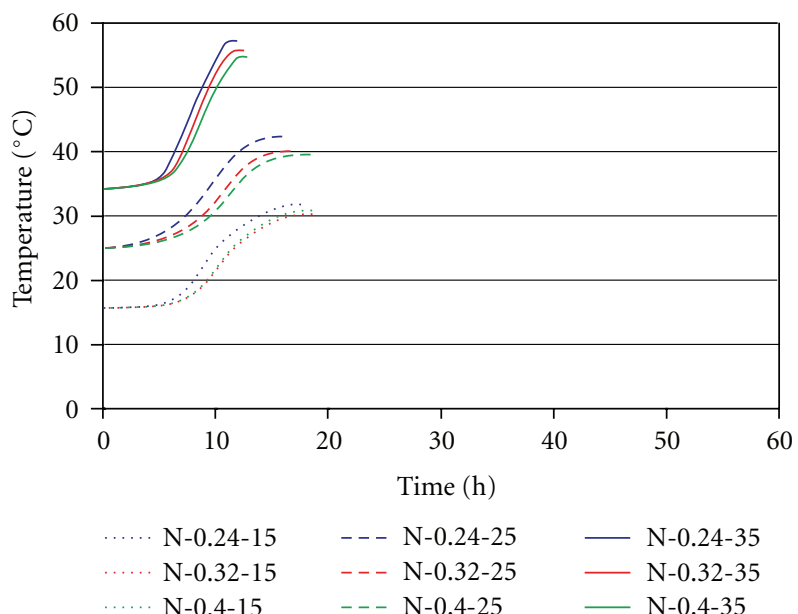

(b) Naphthalene

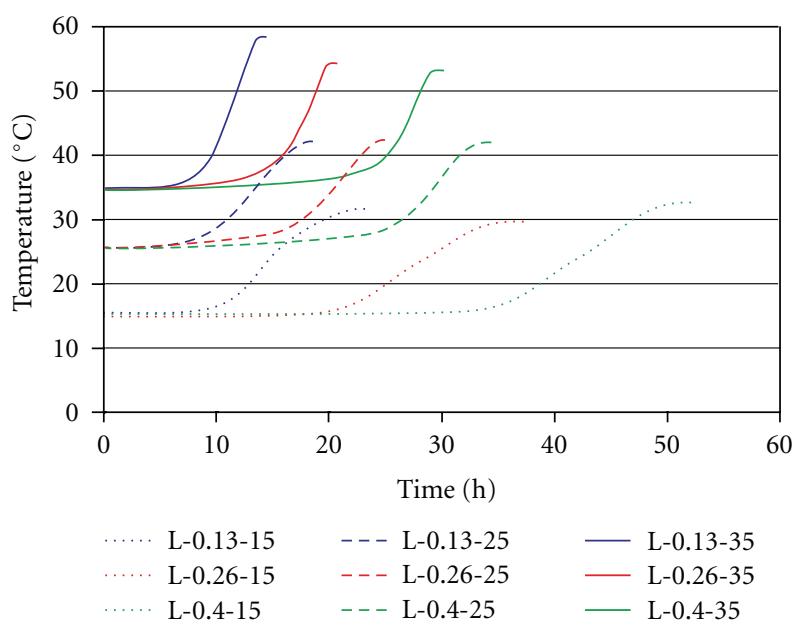

(c) Lignosulphonate

FIgURE 10: Time-temperature curves for the mortar mixtures produced with different admixtures.

it can be seen that at $T=25^{\circ} \mathrm{C}$, naphthalene and lignosulfonate dosages had less effect on compressive strength than polycarboxylate dosage. In the case of lignosulfonate at 


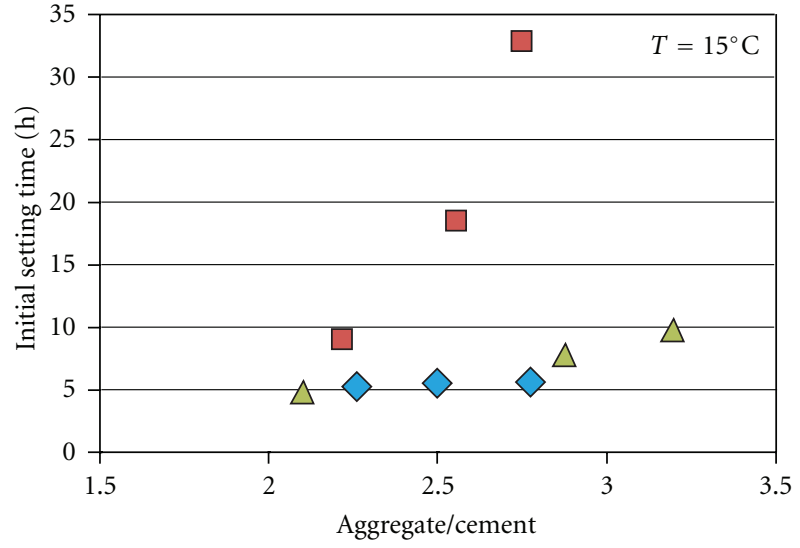

(a)

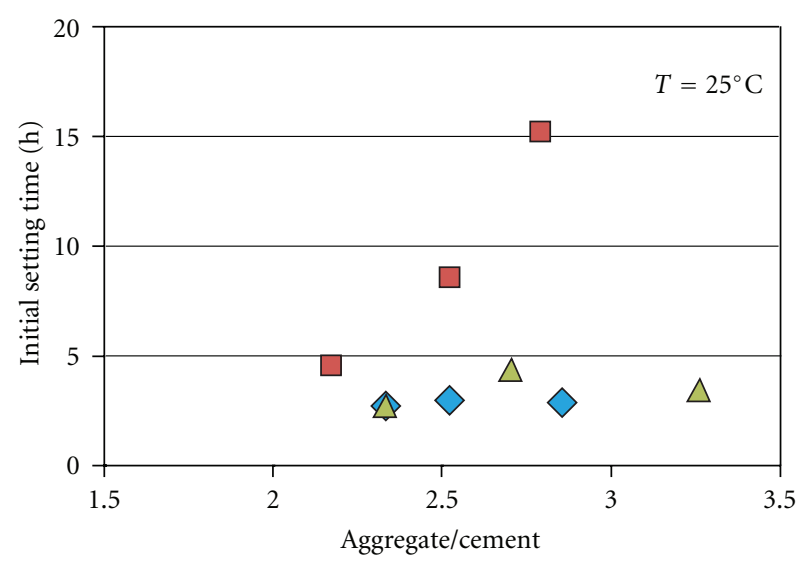

(b)

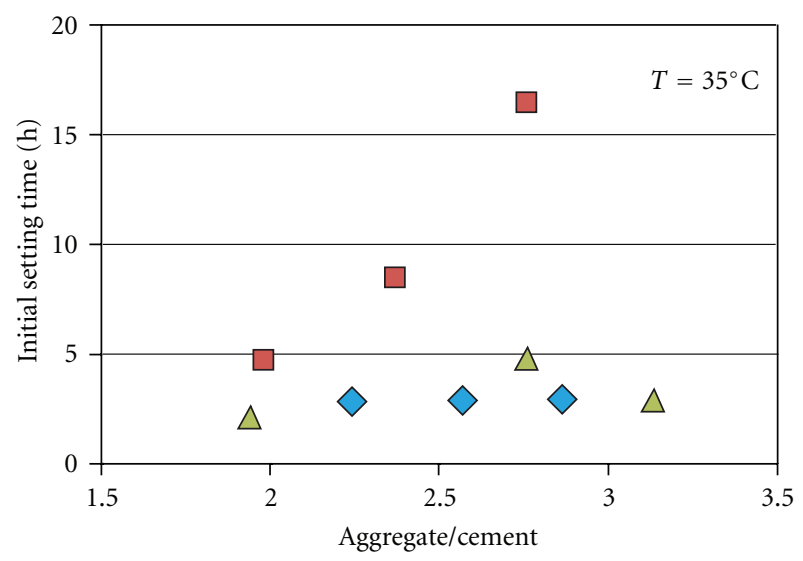

Lignosulfonate

$\diamond$ Naphthalene

$\triangle$ Polycarboxylate

(c)

FIGURE 11: Effect of aggregate/cement content and temperature variation on initial setting time of mortar produces different admixtures dosages.

$15^{\circ} \mathrm{C}$ and $35^{\circ} \mathrm{C}$, results indicate a trend where compressive strength is most elevated when using the intermediate dosage of $0.26 \%$.

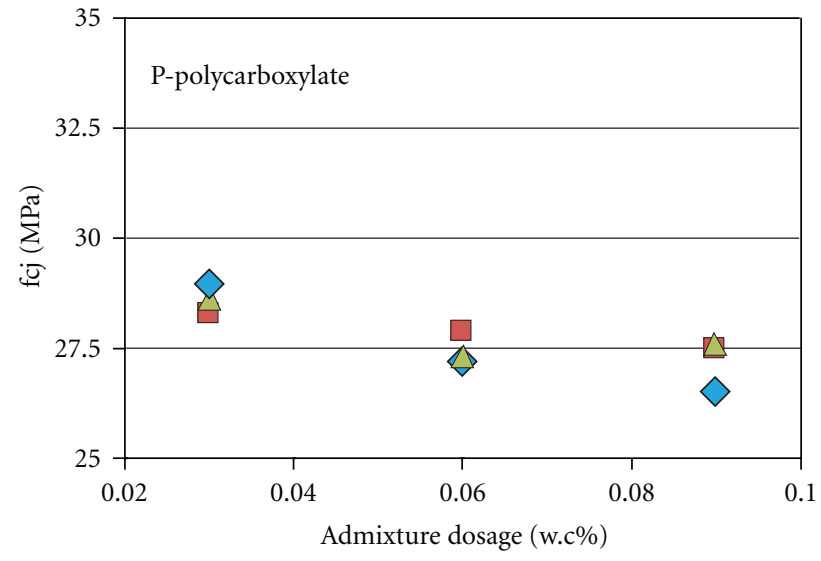

(a)

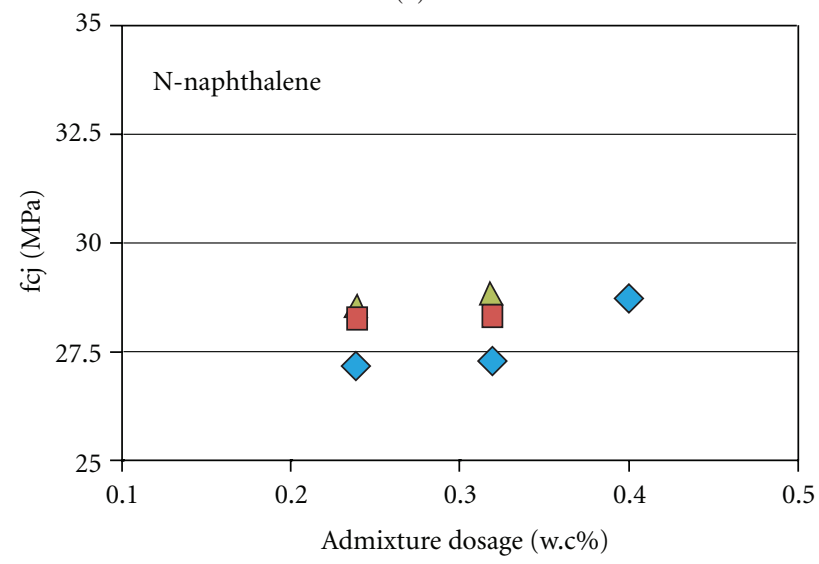

(b)

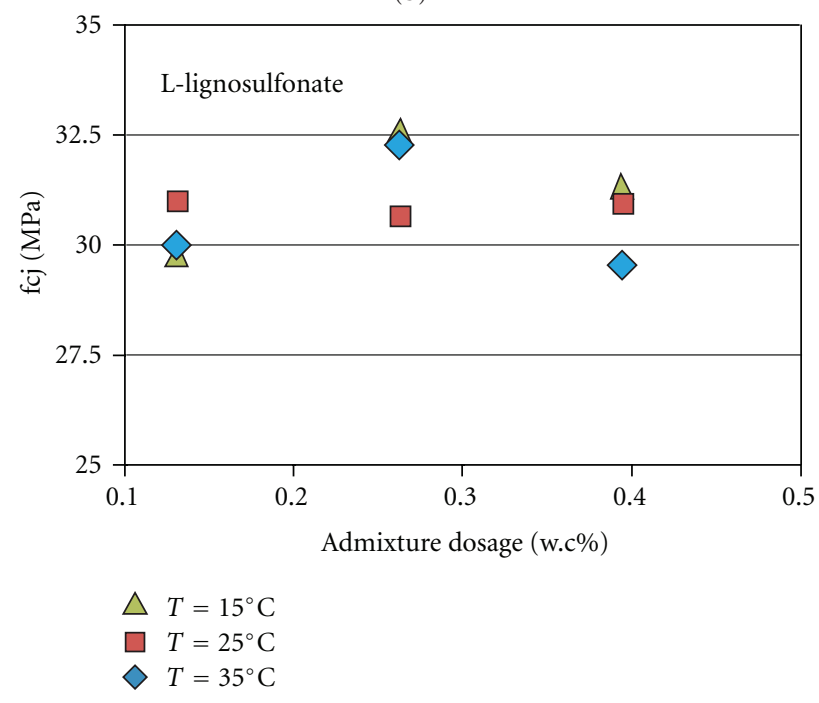

(c)

FIGURE 12: Effect of temperature variation and admixture dosage on compressive strength.

Regarding the influence of temperature variation, also presented in Figures 12(a)-12(c), it appears that the compressive strength of mortars with naphthalene-based admixtures decreases as temperature rises. No such trend was noted for the two other active ingredients. 


\section{Conclusion}

In this study, mortar mixtures containing admixtures based on three different active ingredients were produced and subjected to different temperatures in order to evaluate the effect of temperature on admixture performance. Bearing in mind what materials and dosages were employed in these tests, the following conclusions were reached. Due to variations in the kinetics of hydration reactions, admixture saturation dosage and flow loss performance vary with temperature; an increase in temperature leads to an increase in saturation dosage. With respect to the maximization of sand content, polycarboxylate had the best performance. In regard to initial setting time, lignosulfonate had the most pronounced retarding effect, followed by polycarboxylate, and, finally, naphthalene. A rise in temperature from $15^{\circ} \mathrm{C}$ to $25^{\circ} \mathrm{C}$ was more significant in reducing the initial setting time than an increase from $25^{\circ} \mathrm{C}$ to $35^{\circ} \mathrm{C}$, which had little effect. Considering the weather conditions in the area where the study was carried, the final finding would be that the naphthalene-based admixture had the best performance, given that it leads to low air content, and had little effect on initial setting time. Nevertheless, it should be emphasized that the polycarboxylatebased admixture was used here at dosages lower than those recommended by its manufacturers and employed in industry.

\section{References}

[1] R. Rixom and N. Mailvaganam, Chemical Admixtures for Concrete, E\&FN Spon, London, UK, 3rd edition, 1999.

[2] P. K. Mehta and P. J. M. Monteiro, Concrete: Microstructure, Properties and Materials, PINI, São Paulo, Brazil, 2008.

[3] D. F. Weidmann, A. L. Oliveira, J. Santos, and L. R. Prudêncio Jr., "Comparison of the performance of different water reducing admixtures," in Proceedings of the 48th Congresso Brasileiro de Concreto, Rio de Janeiro, Brazil, 2006.

[4] J. Y. Petit, K. H. Khayat, and E. Wirquin, " Coupled effect of time and temperature on variations of yield value of highly flowable mortar," Cement and Concrete Research, vol. 36, no. 5, pp. 832-841, 2006.

[5] Brazilian Association of Technical Standards, "NBR 5736pozzolanic Portland cement-specification," Rio de Janeiro, Brazil, 1991.

[6] Brazilian Association of Technical Standards, "NBR-NM 248 - aggregates - sieve analysis of fine and coarse aggregates," Rio de Janeiro, Brazil, 2003.

[7] Brazilian Association of Technical Standards, "NBR-NM 46aggregates-determination of material finer than 75 um sieve by washing," Rio de Janeiro, Brazil, 2003.

[8] Brazilian Association of Technical Standards, "NBR-NM 52fine aggregate-determination of the bulk specific gravity and apparent specific gravity," Rio de Janeiro, Brazil, 2009.

[9] L. H. Grierson, J. C. Knight, and R. Maharaj, "The role of calcium ions and lignosulphonate plasticiser in the hydration of cement," Cement and Concrete Research, vol. 35, no. 4, pp. 631-636, 2005.

[10] S. Monosi, G. Moriconi, M. Pauri, and M. Collepardi, "Influence of lignosulphonate, glucose and gluconate on the C3A hydration," Cement and Concrete Research, vol. 13, no. 4, pp. 568-574, 1983. 

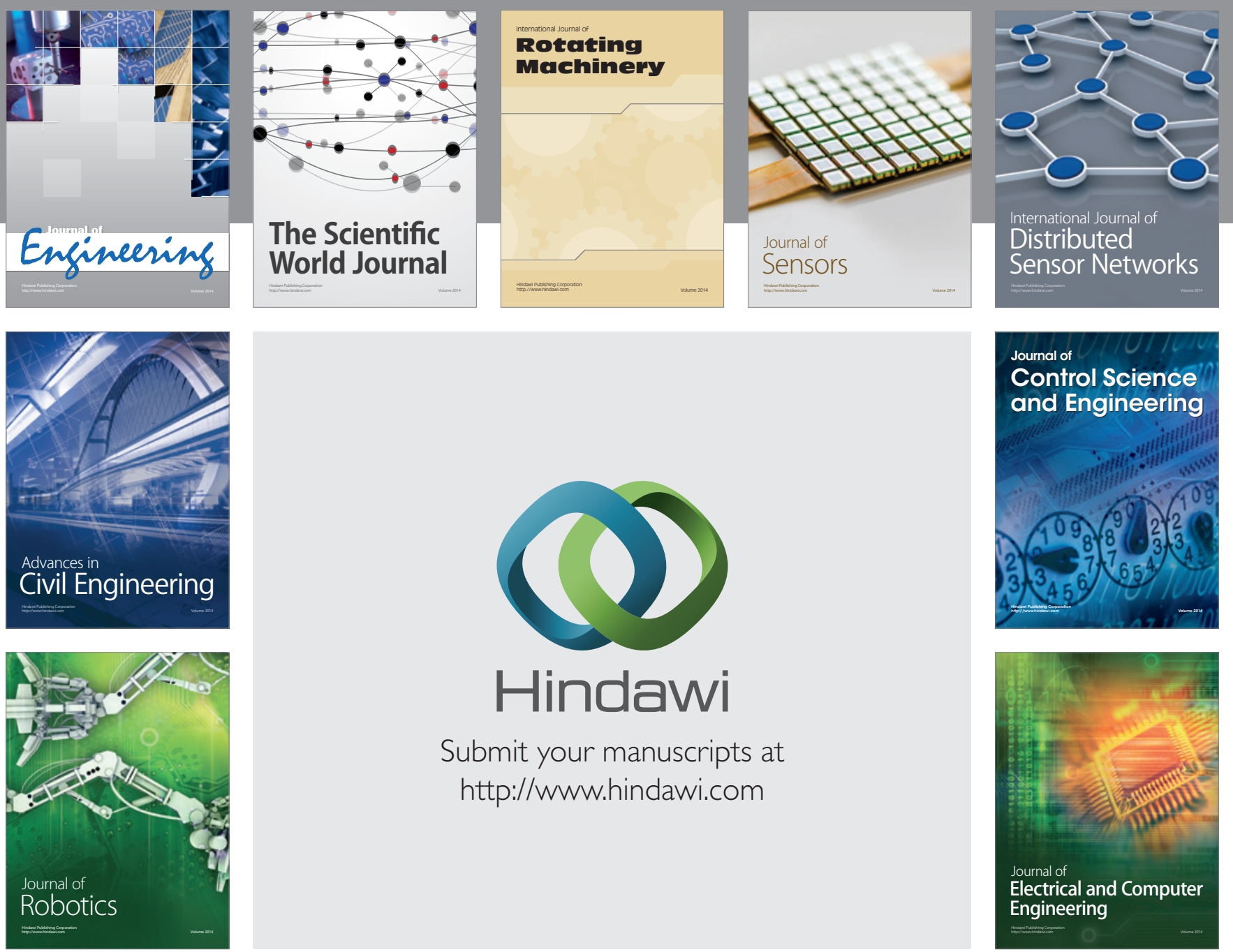

Submit your manuscripts at

http://www.hindawi.com
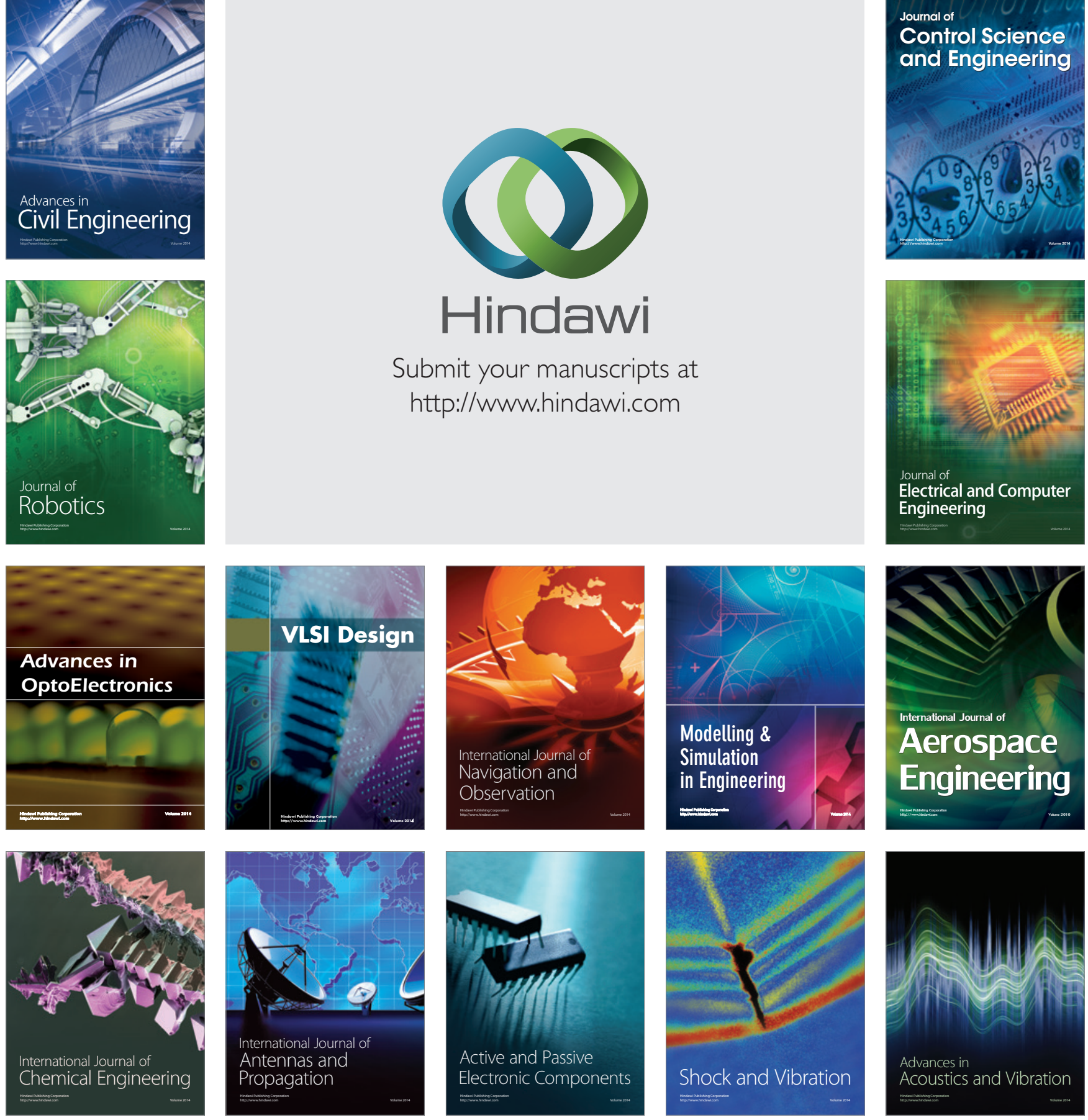